\section{Seed Germination and Seedling Growth of Tomato and Lettuce as Affected by Vermicompost Water Extracts (Teas)}

\author{
Norman Q. Arancon ${ }^{1}$ \\ College of Agriculture, Forestry and Natural Resource Management, \\ University of Hawaii at Hilo, 200 W. Kawili Street, Hilo, HI 96720
}

Archana Pant, Theodore Radovich, and Nguyen V. Hue

College of Tropical Agriculture and Human Resources, University of Hawaii at Manoa, 3190 Maile Way, St. John 102, Honolulu, HI 96822

Jesse K. Potter and Chad E. Converse

College of Agriculture, Forestry and Natural Resource Management, University of Hawaii at Hilo, 200 W. Kawili Street, Hilo, HI 96720

Additional index words. vermicompost water extracts, vermicompost teas, vermicompost growth hormones

\begin{abstract}
Greenhouse experiments were conducted to evaluate the effects of different concentrations of vermicompost water extracts (teas) and seed soaking duration on germination of tomato (Solanum lycopersicum) and lettuce (Lactuca sativa) seeds. In the first experiment, tomato and lettuce seeds were soaked in vermicompost teas prepared from chicken manure-based vermicomposts for 9 hours. The concentrations of the extracts used were $10 \%, 5 \%, 3 \%, 1 \%(1: 10,1: 20,1: 33$, and $1: 100$ vermicompost-to-water ratio by volume), and $0 \%$ (water control). Seeds were sown in peat-perlite medium, and seedlings were harvested after 4 weeks. Soaking seeds in vermicompost teas significantly $(P<0.0001)$ increased germination percentage and seedling growth of tomato and lettuce compared with control. The response to concentrations of the vermicompost tea was generally linear. In another experiment, tea produced from food waste-based vermicompost was used. Tomato seeds were soaked in $20 \%, 10 \%, 5 \%, 1 \%$, and $0 \%$ teas after 24 hours of soaking and sown into a sphagnum moss-based medium. Plant responses were linear and quadratic for germination and growth, respectively, with $1 \%$ vermicompost tea increasing germination, whereas $5 \%$ vermicompost tea significantly promoted growth. A third experiment was done to evaluate the interaction of a range of vermicompost tea concentrations $(20 \%, 10 \%, 5 \%, 1 \%$, and $0 \%)$ and length of soaking $(24,12,8,4,1$ hours, and 0 : no soaking) on the germination of tomato seeds. There was a significant interaction $(P<0.001)$ between the concentration of vermicompost teas and lengths of soaking. Soaking duration generally had a significantly positive and linear effect on germination of tomato seeds across the concentrations of vermicompost tea. Germination rates of tomato seeds were significantly greater after 8, 12, and 24 hours of soaking. However, within each soaking duration, concentrations of vermicompost teas had variable effects on seed germination. The presence of $\mathbf{N}$-indole-3-acetic acid (IAA), cytokinin, gibberellins, and humic acids in the teas could have been responsible for the faster germination of tomato seeds when soaked at lower concentrations and longer soaking times.
\end{abstract}

Vermicompost tea, an aqueous extract of vermicompost, may contain a series of bioactive molecules as well as microbial populations derived from the parent material, which may be enhanced during the production of extracts (Edwards et al., 2006; Ingham, 2005a; Scheuerell and Mahaffee, 2004). Although there is still insufficient information on the chemical and biological properties of vermicompost extracts, water-extractable mineral nutrients and biologically active metabolites such as humic acids as well as

Received for publication 2 July 2012. Accepted for publication 18 Sept. 2012.

${ }^{1}$ To whom reprint requests should be addressed; e-mail normanq@hawaii.edu.
Arancon et al. (2007) and Edwards et al. (2006) demonstrated an enhanced seed germination and growth of tomato and cucumber plants with the application of vermicompost extracts to the growth media. Lazcano et al. (2010) reported the positive effect of vermicompost and vermicompost extract on germination and early development of Pinus pinaster. The objective of this study was to investigate the effect of vermicompost tea concentrations extracted from chicken manurebased or food waste-based vermicomposts and soaking times on the germination rate and early development of tomato and lettuce seedlings. This research consisted of three interrelated experiments. The first experiment investigated the effects of soaking seeds in different vermicompost tea concentrations extracted from chicken manure on the germination and growth tomato and lettuce. It is hypothesized that soaking seeds in vermicompost extracts would contribute to rapid germination of tomato and lettuce seeds and enhance seedling growth. The second experiment further investigates the effects of soaking tomato seeds in vermicompost tea extracted from food waste vermicompost. It is hypothesized that regardless of the source of vermicompost tea, germination and seedling growth rate will increase after soaking in different concentrations. The third experiment investigates the relationships between soaking times and concentrations of different vermicomposts and their effects on germination and seedling growth. It is hypothesized that soaking seeds longer in higher concentrations of vermicompost teas will produce faster germination and increased growth. These effects are non-nutritional and could be the result of presence of other metabolites in teas such as plant growth hormones. All vermicomposts used in the experiments were processed by Eisenia fetida.

\section{Materials and Methods}

Expt. 1. Greenhouse experiments were conducted to test the effect of vermicompost tea on the germination of tomato and lettuce seeds. A 10\% (1:10 vermicompost-to-water ratio by volume) aerated vermicompost extract was prepared using a chicken manurebased vermicompost and water, as described by Pant et al. (2009) and was further diluted with water to make $5 \%, 2 \%$, and $1 \%$ vermicompost extracts, respectively. Tomato and lettuce seeds were soaked for $9 \mathrm{~h}$ in different concentrations of vermicompost extracts $(10 \%, 5 \%, 2 \%$, and $1 \%)$ and in water $(0 \%)$. Seeds were sown in peat-perlite medium and fertilized with chicken manure-based compost to provide $300 \mathrm{mg}$ nitrogen $(\mathrm{N}) / \mathrm{L}$ media $(\approx 150 \mathrm{~kg} \mathrm{~N} / \mathrm{ha})$. Media were sprayed once at the time of sowing with the respective concentration of vermicompost tea that was used for soaking the seeds. Plants were allowed to grow in the greenhouse on benches fitted with overhead sprinklers with a frequency of every $4 \mathrm{~h}$ for $5 \mathrm{~min}$. The experiments were arranged in a completely randomized design with five treatments based on concentrations 
and five replications per treatment. Each replication contained 20 plants and three to five seedlings were sampled from each replication.

Seed germination rate was recorded after $7 \mathrm{~d}$. Seedlings were harvested after 4 weeks of planting. Plant height, aboveground fresh and dry shoot weights, and the number of leaves were measured. Total root length and root surface area were calculated using WinRHIZO Pro V. 2003b system (Regent Instruments Inc., Quebec, Canada). The system consists of a scanner and WinRHIZO software. After taking the root fresh weight, roots were ovendried at $70{ }^{\circ} \mathrm{C}$ for $72 \mathrm{~h}$ and dry weight of the roots of each plant was recorded.

Expt. 2. A 20\% (1:5 vermicompost-towater ratio by volume) aerated vermicompost extract was prepared using food waste-based vermicompost and water, as previously described (Pant et al., 2009) and was further diluted with water to make $10 \%, 5 \%$, and $1 \%$ vermicompost extracts. Tomato seeds were soaked for $24 \mathrm{~h}$ in four concentrations of vermicompost extracts $(20 \%, 10 \%, 5 \%$, and $1 \%)$ and in water $(0 \%)$. Seeds were sown into 7.5-cm $(500-\mathrm{mL})$ pots with Sunshine Mix \#1 medium, which consisted of Canadian sphagnum peatmoss, coarse perlite, starter nutrient (with gypsum), and dolomitic limestone mixture. The medium was watered to field capacity and was sown with 20 seeds. Seeds were allowed to germinate and grow in the greenhouse on a bench fitted with overhead sprinklers with a frequency of every $2 \mathrm{~h}$ for $2 \mathrm{~min}$. The experiment was arranged in a completely randomized design. Each replication contained 20 plants and five seedlings were sampled from each replication.

Seed germination rate was recorded. Seedlings were harvested 8 weeks after planting. Plant height, root length, and root density were measured.

Expt. 3. To evaluate the interaction between vermicompost tea concentrations and duration of soaking, greenhouse experiments were set up consisting of six soaking times ( 0 : no soaking, 1, 4, 8, 12, and $24 \mathrm{~h}$ ) and five vermicompost tea concentration $(0 \%, 1 \%, 5 \%$, $10 \%$, and $20 \%$ ) in a $5 \times 6$ factorial design with five replications. Seed germination rates were assessed after $3 \mathrm{~d}$, which is the first day of seedling emergence, after sowing, and where the differences in the number of seedling emergence between treatments were most evident.

Chemical analysis. The $\mathrm{pH}$ and electrical conductivity (EC) of the compost teas were measured using a conductivity/pH meter (SB80PC, sympHony; VWR Scientific Prod-

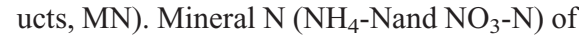
the vermicompost tea was analyzed colorimetrically using a discrete analyzer (Easy Chem Plus; Systea Scientific, IL). Other nutrients of the compost extracts were measured with an inductively coupled plasma spectrometer. Humic acids from compost and compost tea were extracted using the alkali/ acid fractionation procedure (Valdrighi et al., 1996).

Plant growth hormone analysis. A number of phytohormones [e.g., abscisic acid
(ABA) and ABA metabolites, cytokinins, auxins, and gibberellins] of lyophilized compost tea samples were analyzed at the Plant Biotechnology Institute of the National Research Council of Canada (PBI-NRC Saskatoon, Saskatchewan, Canada). Deuterated forms of the hormones that were used as internal standards were synthesized and prepared as described by Abrams et al. (2003) and Zaharia et al. (2005). Multiple phytohormones and metabolites, including auxins (IAA, $\mathrm{N}$-indole3-yl-acetyl-aspartic acid, and N-indole-3yl-acetyl-glutamic acid), abscisic acid, and metabolites ABA, phasic acid, dihydrophasic acid, 7-hydroxy-abscisic acid, neophasic acid abscisic acid glucose ester), cytokinins (isopentyladenine, isopentyladenosine, zeatin, zeatin riboside, dihydrozeatin, dihydrozeatin riboside, and zeatin-O-glucoside), and gibberellins (GAs 1, 3, 4, 7, 8, 9, 19, 20, 24, 29, 34,44 , and 53) were quantified by highperformance liquid chromatography electrospray ionization tandem mass spectrometry as described by Chiwocha et al. (2003, 2005). Calibration curves were generated from the Multiple Reaction Monitoring signals obtained from standard solutions based on the ratio of the chromatographic peak area for each analyte to that of the corresponding internal standard, as described by Ross et al. (2004). Quantifiable results are expressed in nanograms/liter of compost tea samples. If the signals were below the limit of quantification (defined as signal/noise ratio of greater than or equal to $8)$, results are reported as present but nonquantifiable. If the values were below limit of quantification (with a signal/noise ratio less than 3), results are reported as non-detectable.

Analysis of variance of plant growth parameters and seed germination rate was performed using SAS 9.1 statistical software (SAS Institute Inc., 2003). Trend analysis by polynomial regression was conducted for seed germination and measured plant growth parameters between $0 \%$ and $20 \%$ vermicompost tea treatments. Statistical significance was obtained at the $95 \%$ confidence level $(\alpha=0.05)$.

\section{Results}

Teas $(20 \%)$ from chicken manure and food waste vermicompost had similar $\mathrm{pH}$ values, which were close to neutral, $\mathrm{pH} 7.5$ and 7.9, respectively (Table 1). EC values were low for both tea sources but food waste vermicomposts showed much lower value of $0.5 \mathrm{mS} \cdot \mathrm{cm}^{-1}$. Humic acid values of teas from chicken manure and food waste vermicompost were 464.8 and $500 \mathrm{mg} \cdot \mathrm{L}^{-1}$, respectively. Teas from chicken manure-based vermicomposts contained greater concentrations of total $\mathrm{N}, \mathrm{NO}_{3}-\mathrm{N}, \mathrm{NH}_{4}-\mathrm{N}$, phosphorus, potassium, and magnesium but similar calcium levels than from teas extracted from food waste vermicomposts (Table 2). Teas from the chicken manure-based vermicompost contained three types of gibberellins: GA4 (198.1 ng. $\left.\mathrm{L}^{-1}\right)$, GA24 (256.6 ng. $\left.\mathrm{L}^{-1}\right)$, and GA34 (230.1 ng. $\left.\mathrm{L}^{-1}\right)$. GA24 (185 $\left.\mathrm{ng} \cdot \mathrm{L}^{-1}\right)$ was detected in teas extracted from food waste vermicomposts. Additionally, $185.0 \mathrm{ng} \cdot \mathrm{L}^{-1}$ of N-(indole-3-ylacetyl)-leucine (an IAA) and $185.0 \mathrm{ng} \cdot \mathrm{L}^{-1}$ of isopentenyladenine (a cytokinin) were found in the food waste-based vermicompost teas.

\section{Expt. 1}

Tomato. Soaking seeds in vermicompost tea significantly $(P<0.0001)$ increased germination percentage and seedling growth of tomato. Increasing concentrations of the vermicompost tea increased seed germination percentages (Fig. 1) and aboveground fresh shoot weights of tomato seedlings (Fig. 2A), showing a significant $(P<0.0001)$ linear effect. Similar trends were observed in aboveground dry shoot weights, leaf numbers, and heights. Increasing concentration of vermicompost tea increased root fresh weight, resulting in a strong $\left(r^{2}=0.47\right)$ and significant $(P<0.0001)$ linear effect (Fig. 3A). Similar trends were observed in root dry weights, root length, and surface area.

Lettuce. Soaking seeds in vermicompost teas significantly improved germination percentage and seedling growth of lettuce compared with the control. Increasing concentrations of vermicompost tea increased seed germination percentages, resulting in a strong $\left(r^{2}=0.62\right)$ and significant $(P<0.001)$ linear effect (Fig. 1). Increasing concentration of vermicompost tea increased aboveground fresh weight, resulting in a strong $\left(r^{2}=0.62\right)$ and significant $(P<0.0001)$ linear effect (Fig. 2A). Similar trends were observed in aboveground shoot dry weights and heights (Fig. 2A). Leaf numbers were unaffected $(P<0.16)$ by vermicompost tea treatments. Increasing concentrations of vermicompost tea increased root fresh weights, resulting in a strong $\left(r^{2}=0.61\right)$ and significant $(P<0.0001)$ linear effect (Fig. 3A).

Table 1. Chemical properties of the $20 \%(1: 5)$ vermicompost teas $(n=6)$.

\begin{tabular}{lccc}
\hline Compost tea type & Electrical conductivity $\left(\mathrm{mS} \cdot \mathrm{cm}^{-1}\right)$ & $\mathrm{pH}$ & Humic acid $\left(\mathrm{mg} \cdot \mathrm{L}^{-1}\right)$ \\
\hline Chicken manure-based vermicompost & 1.0 & 7.5 & 464.8 \\
Food waste-based vermicompost & 0.5 & 7.9 & 500.0 \\
\hline
\end{tabular}

Table 2. Nutrient concentrations of the 20\% (1:5) vermicompost teas $(n=6)$.

\begin{tabular}{lccccccc}
\hline Compost tea type & Nitrogen & $\mathrm{NO}_{3}-\mathrm{N}$ & $\mathrm{NH}_{4}-\mathrm{N}$ & Phosphorus & Potassium & Calcium & Magnesium \\
\hline $\begin{array}{c}\text { Chicken manure-based } \\
\text { vermicompost }\end{array}$ & 139.1 & 137.9 & 0.6 & 11.0 & 45.1 & 59.6 & 61.6 \\
$\begin{array}{c}\text { Food waste-based } \\
\text { vermicompost }\end{array}$ & 1.66 & 1.0 & 0.5 & $\mathrm{ND}$ & 14.3 & 62.2 & 11.9 \\
\hline
\end{tabular}

$\mathrm{ND}=$ not determined 
Similar trends were observed in root dry weight and root surface area. Increasing concentrations of vermicompost teas increased root lengths, resulting in a strong $\left(r^{2}=0.55\right)$ and significant $(P<0.0001)$ quadratic effect.
Expt. 2

Soaking tomato seeds for $24 \mathrm{~h}$ significantly increased seed germination at $1 \%$ vermicompost teas, whereas germination of seeds soaked in $5 \%$ vermicompost teas was

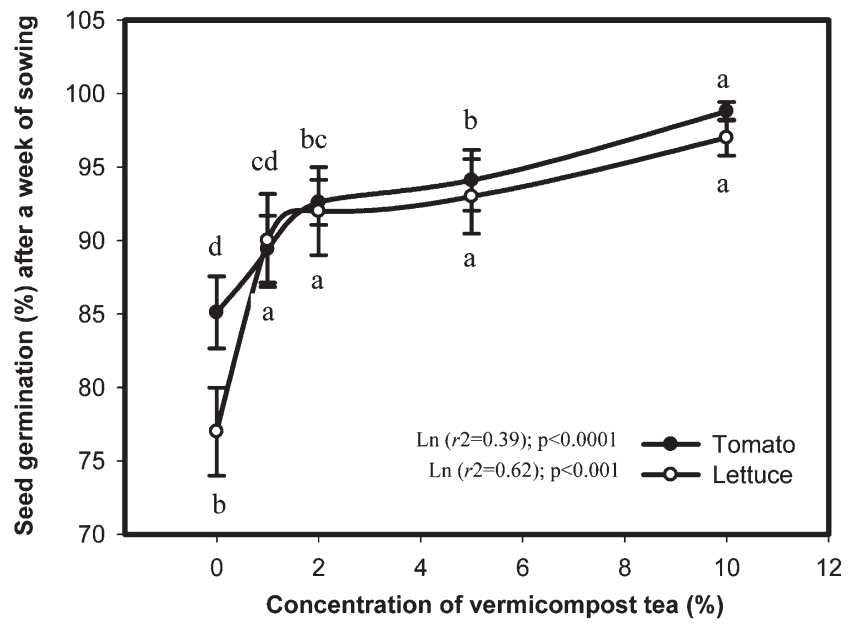

Fig. 1. Seed germination of tomato and lettuce as affected by soaking seeds into chicken manure-based vermicompost tea for $9 \mathrm{~h}$ before sowing. Plotted points are means of 30 samples, and error bars represent SEM. Germination trends of tomato and lettuce seeds with vermicompost tea concentrations were assessed by polynomial regressions and are specified Ln (linear). Means ( \pm SE) designated by the same letter(s) are not significantly different at $P \leq 0.05$.

not significantly different from those of the control (Fig. 4A). Germination decreased significantly $(P<0.001)$ in seeds soaked in $10 \%$ and $20 \%$ vermicompost teas. The response of tomato seed germination to concentrations of vermicompost teas was significantly quadratic $\left(r^{2}=0.91 ; P<0.0001\right)$. Increasing concentrations of vermicompost teas resulted in a significantly quadratic $\left(r^{2}=0.93 ; P<\right.$ $0.0001)$ response in growth of tomato seedlings, in which plant height peaked at 5\% vermicompost tea and significantly decreased at $10 \%$ and $20 \%$ vermicompost concentrations. Significant quadratic relationships between tomato root length $\left(r^{2}=0.38 ; P<\right.$ $0.0005)$ and root density $\left(r^{2}=0.52 ; P<\right.$ $0.0001)$ to increasing concentrations of vermicompost teas from food waste were recorded. Root length and density were consistently and significantly $(P<0.0001)$ greatest at $5 \%$ concentration of vermicompost tea.

Expt. 3

There was a significant interaction $(P<$ 0.001 ) between the duration of soaking times and the concentration of vermicompost teas (Fig. 5). Germination rates varied at each of the durations of soaking as the concentration of vermicompost teas increased. For instance, germination rates exhibited a significant
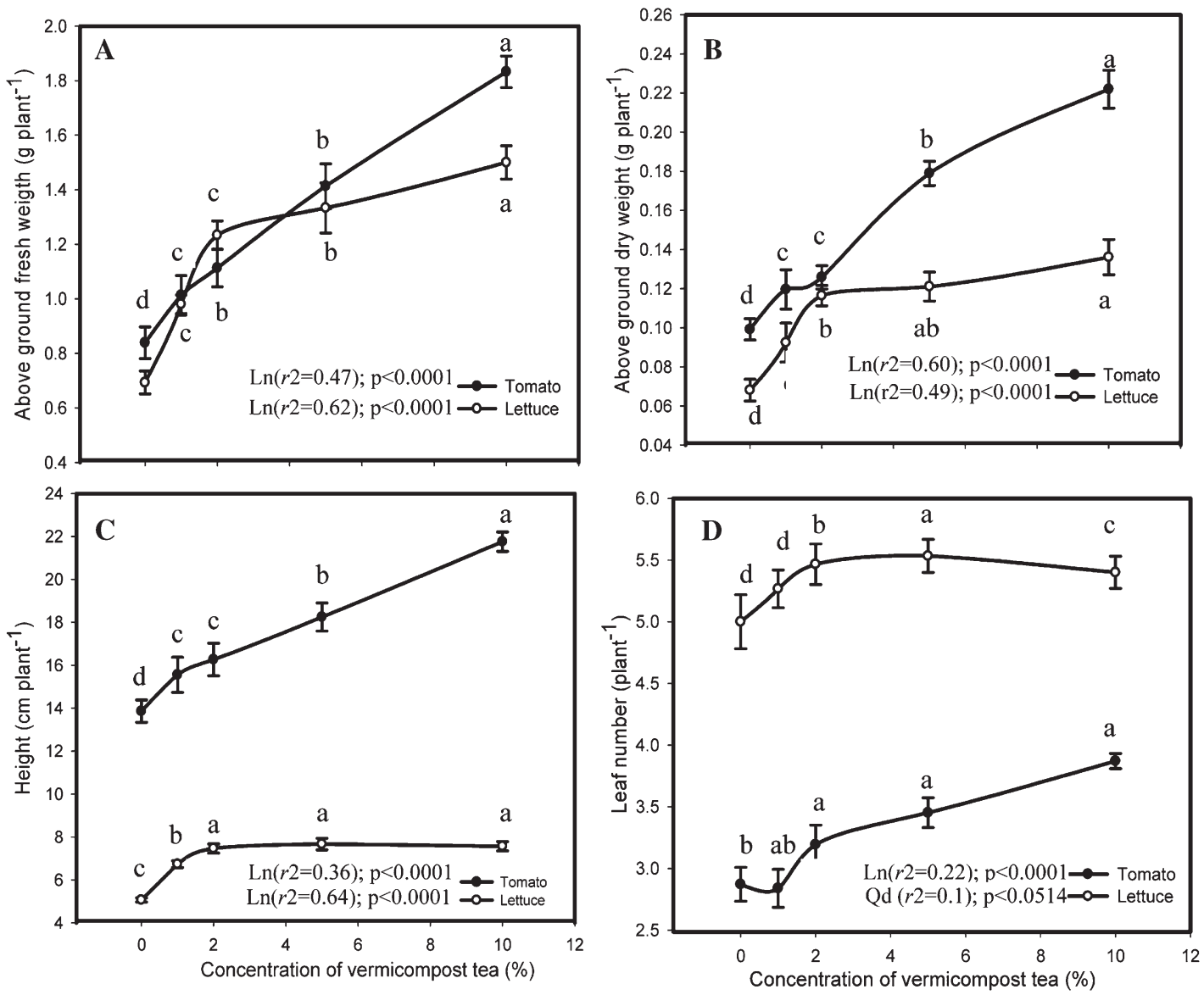

Fig. 2. Effect of the concentration of chicken manure-based vermicompost tea on aboveground plant growth; (A) fresh weight, (B) dry weight, (C) plant height, and (D) leaf number of tomato and lettuce. Plotted points are means of 30 samples, and error bars represent sEM. Trends of tomatoes and lettuce growth with vermicompost tea concentration were assessed by polynomial regressions are specified as Qd (quadratic) and Ln (linear). Means ( \pm SE) designated by the same letter(s) are not significantly different at $P \leq 0.05$. 

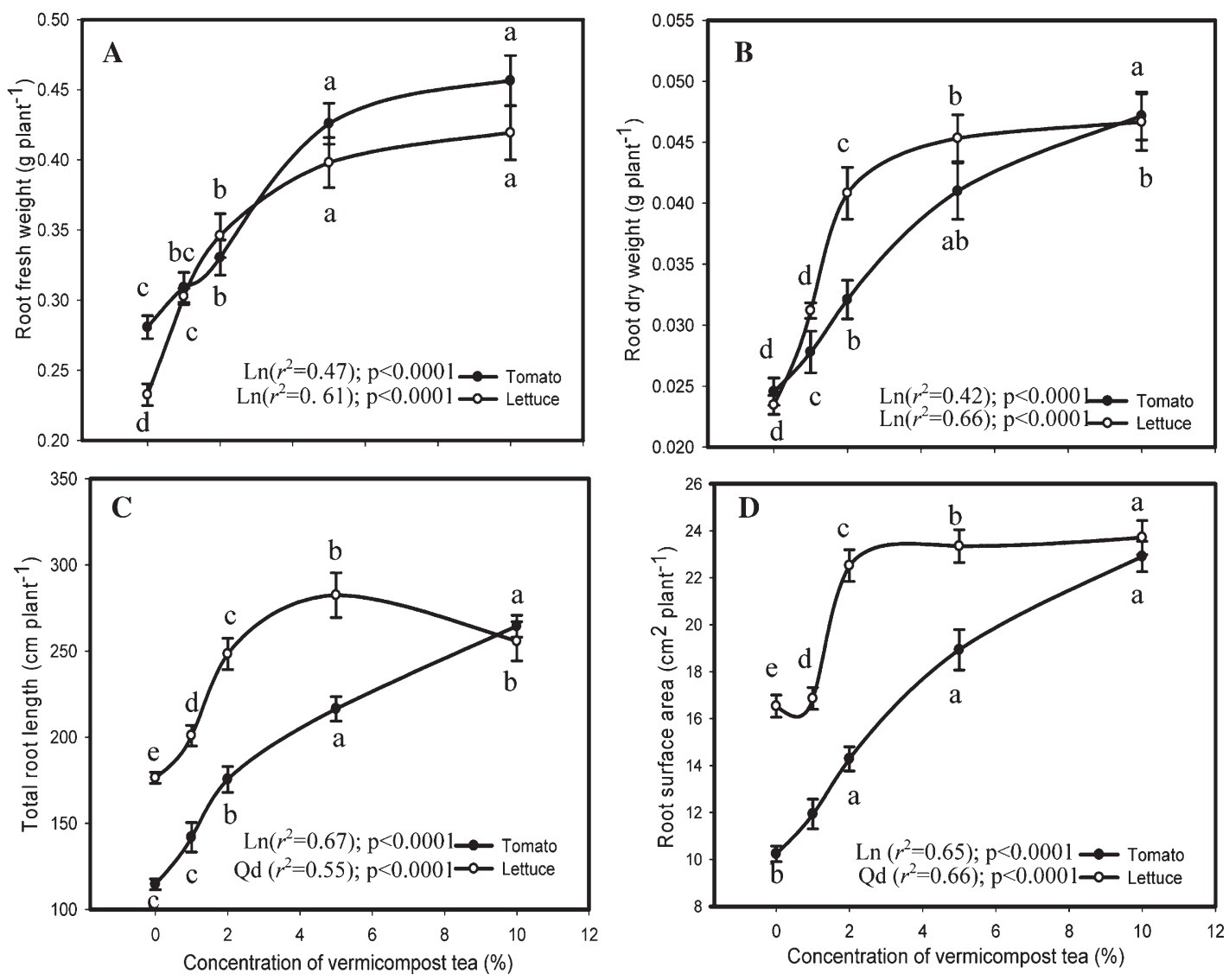

Fig. 3. Effect of the concentration of chicken manure-based vermicompost tea on root growth; (A) root fresh weight, (B) root dry weight, (C) total root length, and (D) root surface area of tomato and lettuce. Plotted points are means of 30 samples, and error bars represent sEm. Trends of tomato and lettuce growth with vermicompost tea concentration were assessed by polynomial regressions are specified as Qd (quadratic) and Ln (linear). Means ( \pm SE) designated by the same letter(s) are not significantly different at $P \leq 0.05$.

quadratic response $\left(r^{2}=0.69 ; P<0.0003\right)$ to increases in concentration of vermicomposts and were significantly $(P<0.05)$ greatest at $1 \%$ and $5 \%$ after $1 \mathrm{~h}$ of soaking. Germination rates were significantly linear $\left(r^{2}=0.54 ; P<\right.$ $0.0006)$, quartic $\left(r^{2}=0.53 ; P<0.0005\right)$, and linear $\left(r^{2}=0.57 ; P<0.0005\right)$ in response to increases in vermicompost concentrations at 4,12 , and $24 \mathrm{~h}$ of soaking times, respectively. In all of the treatments, the $5 \%$ concentration consistently and significantly $(P<0.001)$ produced the highest germination rate. All germination rates were not significantly different for all concentrations after $8 \mathrm{~h}$ of soaking.

At each vermicompost tea concentration, germination rates exhibited significant linear responses $(P<0.001)$ to duration of soaking except those in $20 \%$ vermicompost teas in which germination had a significant quadratic response $\left(r^{2}=0.64 ; P<0.0003\right)$ to duration of soaking times, which peaked between 8 and $12 \mathrm{~h}$ of soaking (Fig. 6).

\section{Discussion}

Although seed germination is an internally regulated process influenced by genotype, external factors such as light, temperature, moisture, and the presence of certain chemical compounds (phytohormones or organic acids) also strongly influence this process (Finkelstein, 2004; Kucera et al., 2005).
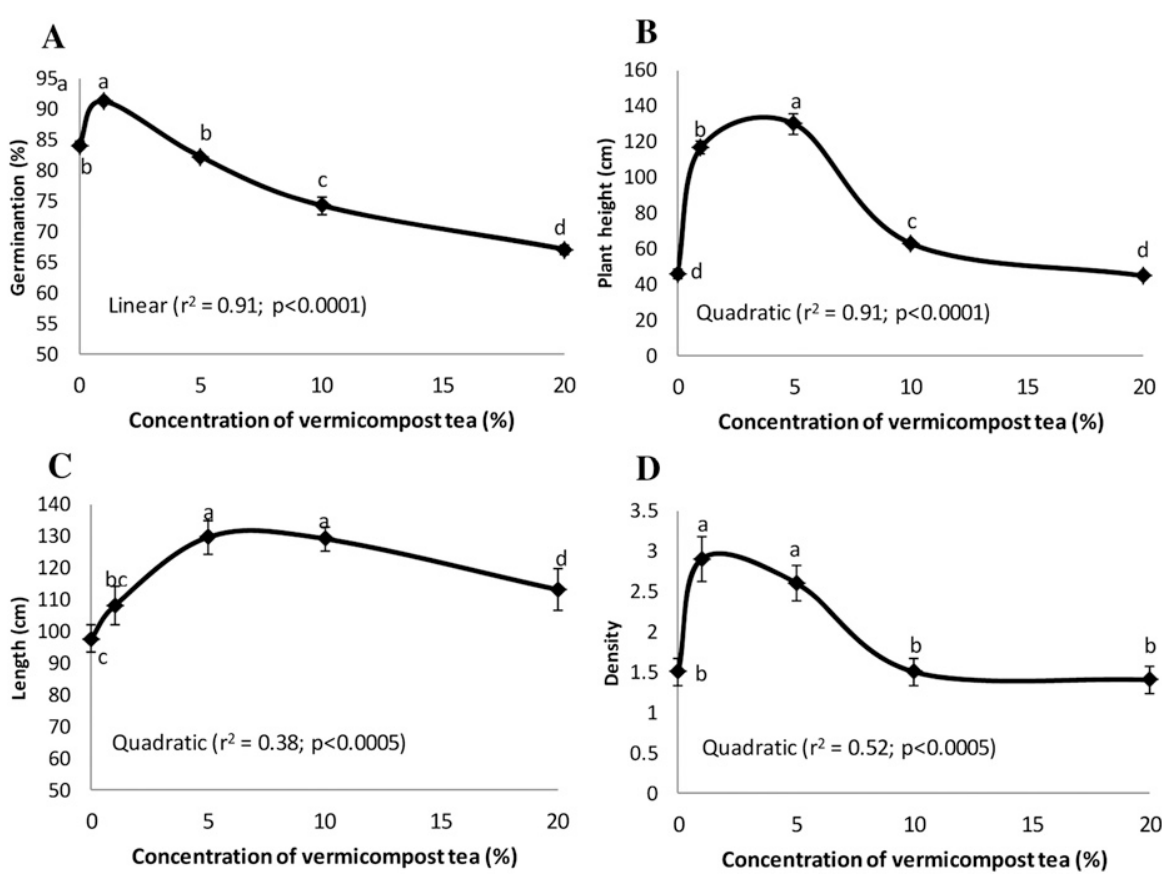

Fig. 4. Effect of the concentration of vermicompost tea produced from food waste-based vermicompost on (A) germination, (B) plant height, (C) root length, and (D) root density. Trends of tomato growth with vermicompost tea concentration were assessed by polynomial regressions are specified as Qd (quadratic) and Ln (linear). Means $( \pm \mathrm{SE})$ designated by the same letter(s) are not significantly different at $P \leq 0.05$. 


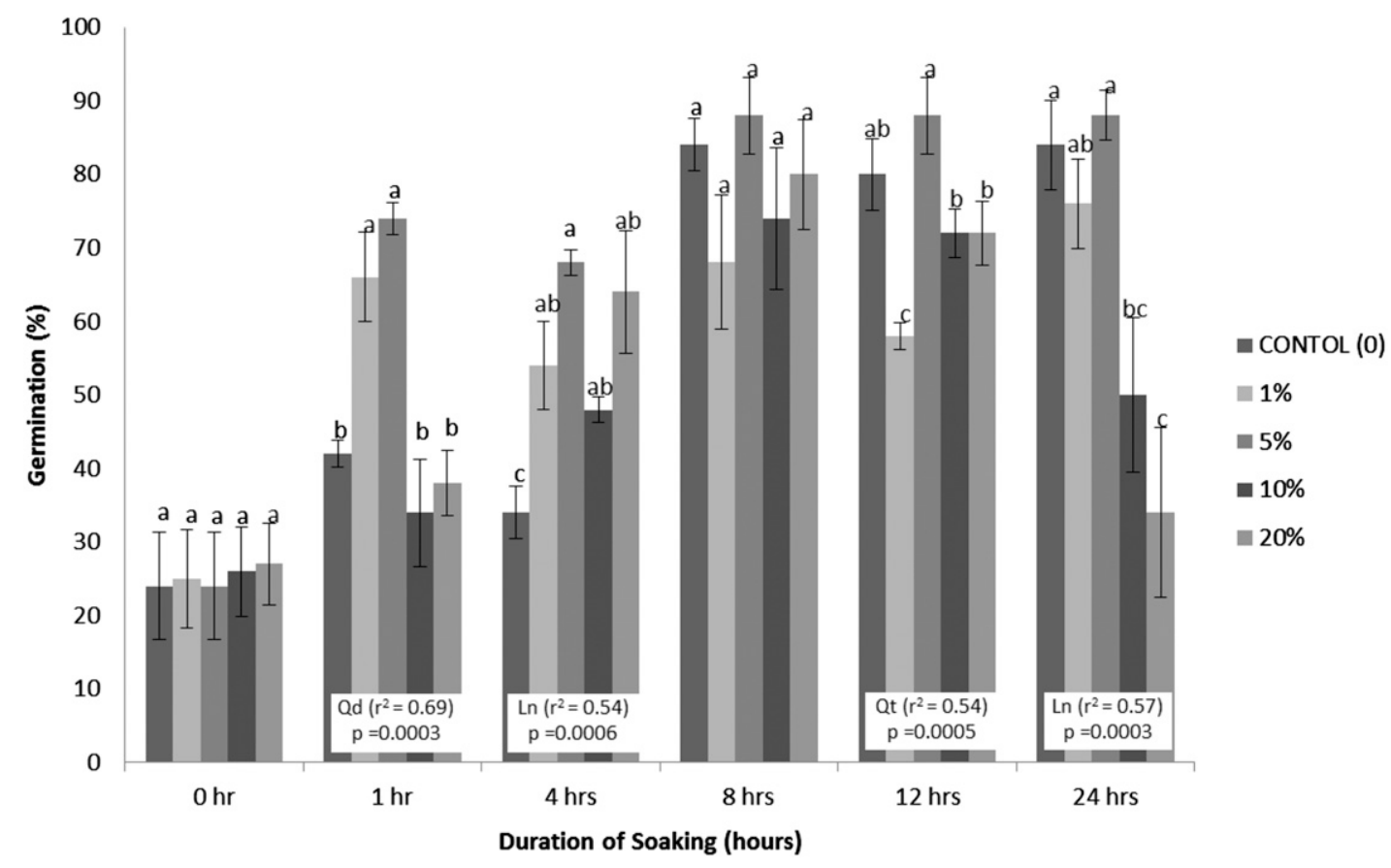

Fig. 5. Germination percentages of tomato seeds exposed to different duration of soaking times $\times$ different concentrations of vermicompost water extracts (teas). Means $( \pm \mathrm{SE})$ followed by the same letter(s) within each soaking time are not significantly different. Trends of germination affected by vermicompost tea concentration $\times$ duration of soaking assessed by polynomial regressions are specified as Qd (quadratic); Ln (linear); and Qt (quartic).

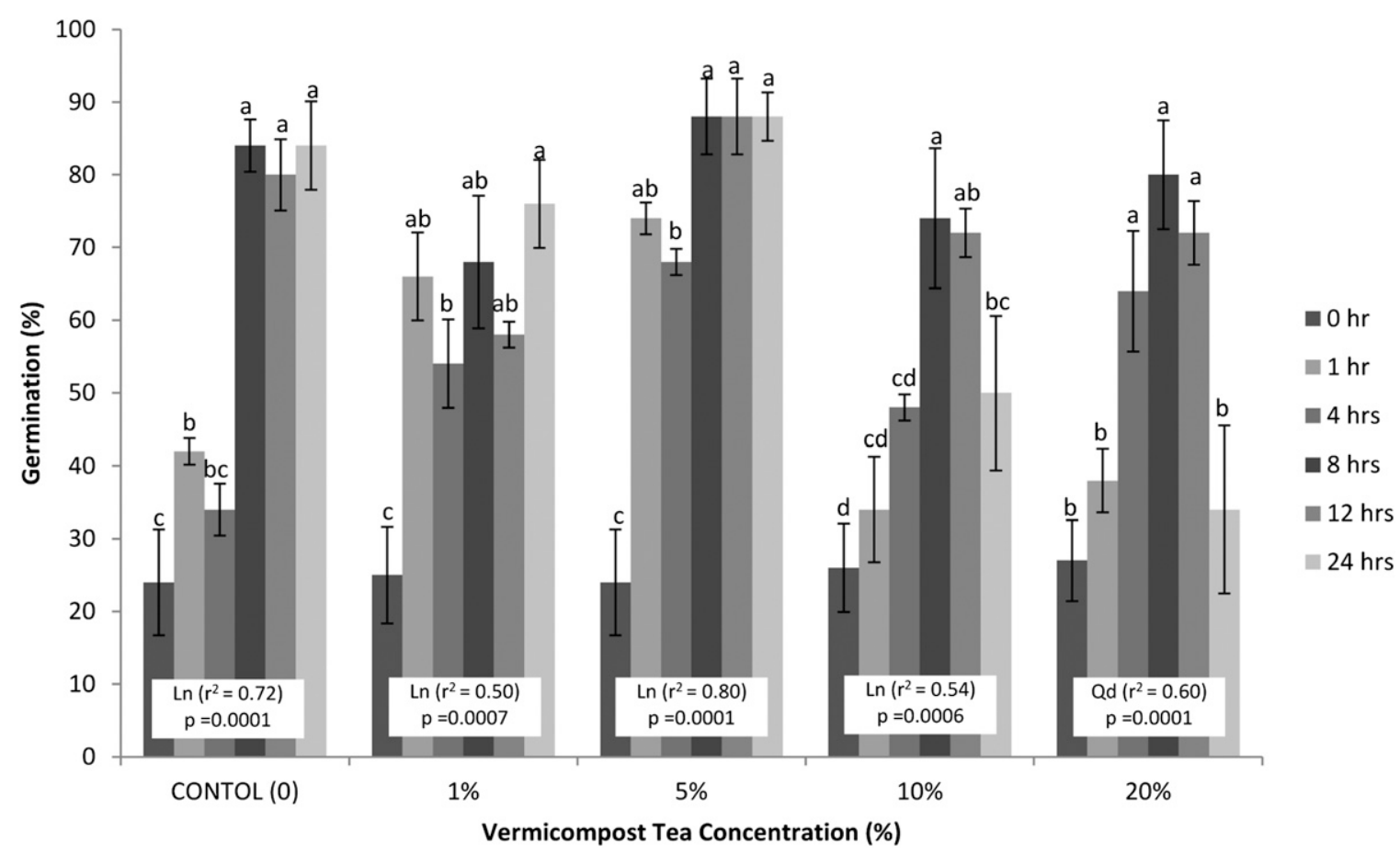

Fig. 6. Germination rates of tomato seeds exposed to different concentrations of vermicompost water extracts (teas) $\times$ different duration of soaking times. Means $( \pm \mathrm{SE})$ followed by the same letter(s) within each vermicompost tea concentrations are not significantly different. Trends of germination affected by duration of soaking $\times$ vermicompost tea concentration assessed by polynomial regressions are specified as Qd (quadratic); Ln (linear); and Qt (quartic).

Moisture content of seed or growth media is one of the important external factors affecting seed germination. Seed soaking can soften a hard seedcoat and also leach out any chemical inhibitors in the seed, which may prevent germination. In this experiment, germination percentage increased when the seeds were soaked in vermicompost extract from chicken manure compared with seeds soaked in water. This suggests that factors beyond physical alteration of seedcoats were responsible for earlier and better germination. Spaccini et al. (2008) reported that aerated compost extracts contained low-molecularweight bioactive compounds of microbial origin. Arancon et al. (2007) demonstrated that the application of a vermicompost extract to growth media enhanced seed germination and seedling growth of tomatoes and cucumbers. Lazcano et al. (2010) reported positive effects of vermicompost extracts on the germination and early development of Pinus pinaster. Better root and shoot growths of both tomato and lettuce seedlings observed 
Table 3. Phytohormones present in the $20 \%$ vermicompost teas $(n=3)$.

\begin{tabular}{|c|c|c|c|c|c|c|}
\hline \multirow[b]{3}{*}{ Compost tea } & \multirow{2}{*}{$\frac{\text { Auxin }}{\text { IAA-leu }}$} & \multicolumn{2}{|c|}{ Cytokinins } & \multicolumn{3}{|c|}{ Gibberellins } \\
\hline & & iPA & $2 \mathrm{iP}$ & GA4 & GA24 & GA34 \\
\hline & ------- & -1--- & $\mathrm{L}^{-1} \mathrm{c}$ & ost tea & - & -------- \\
\hline Chicken manure-based vermicompost & $\mathrm{nq}$ & $\mathrm{nq}$ & $\mathrm{nq}$ & 198.1 & 265.6 & 230.1 \\
\hline Food waste-based vermicompost & 185.0 & 185.0 & & - & 185.0 & - \\
\hline
\end{tabular}

IAA-leu = N-(indole-3-yl-acetyl)-leucine; iPA = isopentyladenosine; $2 \mathrm{iP}=$ isopentyladenine; GA $=$ gibberellin; $\mathrm{nq}=$ non-quantifiable.

in this study agree with the findings of previous studies (Arancon et al., 2007; Lazcano et al., 2010). It is expected that water-soluble bioactive substances such as humic acids, phytohormones, or other microbial metabolites present in vermicompost extract could be responsible for earlier emergence, increased seed germination percentage, and seedling growth. Presence of a small quantity $\left(198 \mathrm{ng} \cdot \mathrm{L}^{-1}\right)$ of GA4 in $10 \%$ chicken manure-based vermicompost tea also suggests the possibility of hormonal effects on seed germination and better root growth. Pant (2011) and Pant et al. (2012) found a positive effect of GA4 on root and shoot growth of in vitro-cultured pak choi with similar concentration as that of the chicken manure-based vermicompost tea used in this study. Enhanced root growth at earlier stages of development may have contributed to better seedling growth. However, a different scenario in germination of tomato seeds was shown in Expt. 2 using a food waste vermicompost in which germination exhibited a quadratic response to concentration that peaked at $1 \%$ and started declining at a linear rate from $5 \%$ to $20 \%$. Clearly, vermicomposts of different origins can produce teas that will affect seed germination and seedling growth differently. Furthermore, the increases in percent germination rates could not have accounted for increases in plant nutrients supplied by vermicompost teas compared with those that only received water. The non-nutritional response was confirmed by the decreases in percent germination rates at higher concentrations of vermicompost teas, especially where the only possible source of nutrition was the vermicompost teas. This could have led to a positive linear response of growth to increases in vermicompost tea concentrations such as the condition exemplified on Expt. 2. The quadratic responses of plant height, root length, and density are typical curve responses of plant growth to presence of other plant growth hormones such as auxins. The teas from food waste vermicompost that were used in the Expts. 2 and 3 contained plant growth hormones such as $185 \mathrm{ng} \cdot \mathrm{L}^{-1}$ of $\mathrm{N}$-(indole-3yl-acetyl)-leucine, an auxin, $185 \mathrm{ng} \cdot \mathrm{L}^{-1}$ of isopentenyladenine, a cytokinin, and $185 \mathrm{ng} \cdot \mathrm{L}^{-1}$ of GA24, a gibberellin (Table 3). These hormones, in addition to $500 \mathrm{mg} \cdot \mathrm{L}^{-1}$ of humic acids in food waste vermicompost teas, could have been responsible for the significant increases in germination. Germination peaked at a concentration of $1 \%$. However, plant height and root length peaked when tomato seeds were soaked in $5 \%$ vermicompost teas. Canellas et al. (2000) found presence of auxin analogs from vermicomposts produced from cattle manure and suggested that these chemicals increased lateral root emergence, root elongation, and plasma membrane $\mathrm{H}+$ ATPase activities of maize roots. Greater concentrations of teas, i.e., $20 \%$, which could provide greater amounts of auxins, cytokinins, and humic acids in Expt. 2 , did not cause any more growth increases of tomato seedlings compared with the control. Expt. 3 confirmed further that, although seed soaking in vermicompost teas generally enhanced germination of tomatoes, lower concentrations of vermicompost teas, i.e., $1 \%$ and $5 \%$, can significantly increase germination consistently after 1 to $24 \mathrm{~h}$ of soaking. Additionally, Expt. 3 also confirmed that higher concentrations of vermicompost teas could be detrimental to germination rates. This is in agreement with previous findings by Arancon et al. (2006) who reported that the effects of the application of humic acids on plants, in which growth of marigolds decreased when grown in a soilless media that contained a combination of $10 \mu \mathrm{M}$ IAA and $500 \mathrm{mg} \cdot \mathrm{kg}^{-1}$ humic acids from food waste vermicomposts. It should be noted that the teas used in the second experiment marginally recorded a slightly greater humic acid content compared with chicken manure-based vermicompost used in Expt. 1. Although these amounts are similar, it should also be noted that the compositions and mode of action of two humic acids could be different. Expt. 2 showed that vermicompost tea can increase germination, but these increases do not always produce more vigorous seedlings. This was the case of tomato seeds soaked in $5 \%$ vermicompost teas for $24 \mathrm{~h}$, which had a significantly lower germination percentage than those soaked in $1 \%$ vermicompost tea but produced seedlings that were taller, had longer roots, and greater root density.

\section{Conclusion}

Seed treatments with vermicompost teas had stimulatory effects on seed germination and seedling growth of both of tomato and lettuce. This suggests those vermicompost teas can be used to speed up vegetable seed germination and to accelerate seedling development. Greater amounts of nutrients in chicken manure-based vermicompost teas seemed to promote a linear increase in germinations and growth of tomatoes and lettuce. Moreover, a combination of low concentration of nutrients; traces of plant growth hormones such as IAA, cytokinins, and gibberellins; and reasonable quantities of humic acids in food waste vermicompost teas can promote germination (i.e., $1 \%$ and $5 \%$ teas). Tomato seeds soaked in lower concentrations of vermicompost teas (1\% and 5\%) increased germination rates when durations of soaking were longer ( 8 to $24 \mathrm{~h}$ ). The effects of these concentrations in relation to soaking time on final yields of tomatoes and lettuce warrant further investigation.

\section{Literature Cited}

Abrams, S.R., K. Nelson, and S.J. Ambrose. 2003. Deuterated abscisic acid analogs for mass spectrometry and metabolism studies. J. Labelled Compd. Rad. 46:273-283.

Arancon, N.Q., C.A. Edwards, R. Atiyeh, and J.D. Metzger. 2004. Effects of vermicomposts produced from food waste on the growth and yields of greenhouse peppers. Bioresour. Technol. 93:139-144.

Arancon, N.Q., C.A. Edwards, P. Bierman, J.D. Metzger, S. Lee, and C. Welch. 2003. Effects of vermicomposts on growth and marketable fruits of field grown tomatoes, peppers and strawberries. Pedobiologia (Jena) 47:731-735.

Arancon, N.Q., C.A. Edwards, R. Dick, and L. Dick. 2007. Vermicompost tea production and plant growth impacts. Biocycle 48:51-52.

Arancon, N.Q., C.A. Edwards, S. Lee, and R. Byrne. 2006. Effects of humic acids from vermicomposts on plant growth. Eur. J. Soil Sci. 42:S65S69.

Atiyeh, R.M., N. Arancon, C.A. Edwards, and J.D. Metzger. 2000a. Earthworm-processed organic wastes as components of horticultural potting media for growing marigold and vegetable seedlings. Compost Sci. Util. 8:215-223.

Atiyeh, R.M., S. Subler, C.A. Edwards, G. Bachmann, J.D. Metzger, and W. Shuster. 2000b. Effects of vermicomposts and composts on plant growth in horticultural container media and soil. Pedobiologia (Jena) 44:579-590.

Canellas, L.P., F.L. Olivares, A.L. Okorokova, and A.R. Facanha. 2000. Humic acids isolated from earthworm compost enhance root elongation, lateral root emergence, and plasma $\mathrm{H}+$-ATPase activity in maize roots. Plant Physiol. 130: 1951-1957.

Chiwocha, S.D.S., S.R. Abrams, S.J. Ambrose, A.J. Cutler, M. Loewen, A.R.S. Ross, and A.R. Kermode. 2003. A method for profiling classes of plant hormones and their metabolites using liquid chromatography-electrospray ionization tandem mass spectrometry: Analysis of hormone regulation of thermodormancy of lettuce (Lactuca sativa L.) seeds. Plant J. 3: 405-417.

Chiwocha, S.D.S., A.J. Cutler, S.R. Abrams, S.J. Ambrose, J. Yang, A.R.S. Ross, and A.R. Kermode. 2005. The etr1-2 mutation in Arabidopsis thaliana affects the abscisic acid, auxin, cytokinin and gibberellin metabolic pathways during maintenance of seed dormancy, moist-chilling and germination. Plant J. 42:35-48.

Edwards, C.A., N.Q. Arancon, and S. Greytak. 2006. Effects of vermicompost teas on plant growth and disease. Biocycle 47:28-31.

Finkelstein, R.R. 2004. Hormones in seed development and germination, p. 513-537. In: Davies, P.J. (ed.). Plant hormones: Biosynthesis, signal transduction and action. Kluwer Academic Publishers.

Ingham, E.R. 2005a. The compost tea brewing manual; latest methods and research. Soil Food Web Inc., Corvallis, OR.

Kucera, B., M.A. Cohn, and G. Leubner-Metzger. 2005. Plant hormone interactions during seed dormancy release and germination. Seed Sci. Res. 15:281-307. 
Lazcano, C., L. Sampedro, R. Zas, and J. Domı'nguez. 2010. Vermicompost enhances germination of the maritime pine (Pinus pinaster Ait.). New For. 39: $387-400$

Pant, A. 2011. Vermicompost tea: effects on pak choi (Brassica rapa cv Bonsai, Chinensis group) growth and yield, phytonutrient content and soil biological properties. PhD diss., University of Hawaii at Manoa, Manoa, HI.

Pant, A., T.J.K. Radovich, N.V. Hue, S.T. Talcott, and K.A. Krenek. 2009. Vermicompost extracts influence growth, mineral nutrients, phytonutrients and antioxidant activity in pak choi (Brassica rapa cv. Bonsai, Chinensis group) grown under vermicompost and chemical fertilizer. J. Sci. Food Agr. 89:2383-2392.

Pant, A., T.J.K. Radovich, N.V. Hue, and R. Paull. 2012. Biochemical properties of compost tea associated with compost quality and effects on pak choi growth. Oral Presentation (Abstract \#10465), American Society of Horticultural Science Annual Conference, Miami, FL, 31 July to 3 Aug. 2012.

Ross, A.R.S., S.J. Ambrose, A.J. Cutler, J.A Feurtado, A.R. Kermode, K. Nelson, R. Zhou, and S.R. Abrams. 2004. Determination of endogenous and supplied deuterated abscisic acid in plant tissues by high performance liquid chromatography-electrospray ionization tandem mass spectrometry with multiple reaction monitoring. Anal. Biochem. 329:324-333.

SAS Institute Inc. 2003. Proc. of the Twenty-Eighth Annual SAS ${ }^{\circledR}$ Users Group International Conference. SAS Institute Inc., Cary, NC

Scheuerell, S.J. and W.F. Mahaffee. 2004. Compost tea as a container medium drench for suppressing seedling damping-off caused by Pythium ultimum. Phytopathology 94:1156-1163.

Spaccini, R., S. Baiano, G. Giliotti, and A. Piccolo. 2008. Molecular characterization of a compost and its water soluble fractions. J. Agr. Food Chem. 56:1017-1024.

Valdrighi, M.M., A. Pera, M. Agnolucci, S. Frassinetti, D. Lunardi, and G. Vallini. 1996. Effects of compost-derived humic acids on vegetable biomass production and microbial growth within a plant (Cichorium intybus)-soil system: A comparative study. Agr. Ecosyst. Environ. 58:133-144.

Zaharia, L.I., M.M. Galka, S.J. Ambrose, and S.R. Abrams. 2005. Preparation of deuterated abscisic acid metabolites for use in mass spectrometry and feeding studies. J. Labelled Compd. Rad. 48:435-445. 